\title{
SISTEM MONITORING PENGONTROL SUHU DAN INTENSITAS CAHAYA PADA PENETAS TELUR PUYUH
}

\author{
Ibrahim Rizki ${ }^{1)}$; Kustanto ${ }^{2)}$; Sri Siswanti ${ }^{3)}$ \\ 1,2,3) Program Studi Teknik Informatika, STMIK Sinar Nusantara \\ ${ }^{1) i b r a r i z 03 @ g m a i l . c o m, ~}{ }^{2)}$ kustanto@sinus.ac.id, ${ }^{3)}$ syswanty@sinus.ac.id
}

\begin{abstract}
Hatching eggs is important in the creation of excellent seeds. Accuracy of care of room temperature conditions and microcontroller based monitoring system is one of the first steps to meet the needs of quality quail seeds in the market. At the same time naturally it is very difficult, because the parent quail is only able to incubate about 5 eggs. The use of automatic egg hatchery is one of the solutions. In this Scripsir research is made automatic quail egg machine based on microcontroller atmega328. The control is able to control the temperature and humidity needed in hatching eggs. From the control result using microcontroller, lamp and fan can be adjusted according to the temperature of the room on the egg hatch is by automatic control of the lamp life and the fan. Test results showed that an increase in hatching eggs by $13 \%$.

Keywords: Hatching eggs, Monitoring system, Climate control, Microcontroller.
\end{abstract}

\section{PENDAHULUAN}

Pangan merupakan satu dari tiga kebutuhan pokok manusia. Melihat hal tersebut tentu menjadikan hal ini sangat penting bagi manusia. Salah satu jenis pangan yang cukup diminati untuk di konsumsi adalah telur, khususnya telur puyuh.

Namun yang menjadi permasalahan adalah bagaimana untuk menetaskan telur puyuh dalam jumlah banyak dan dalam waktu yang bersamaan. Karena kemampuan induk puyuh dalam mengerami telurnya terbatas, yaitu maksimal 5 butir telur tiap induk puyuh. Ini menjadi masalah yang serius karena kebutuhan daging dan telur puyuh di pasar yang sangat banyak. Maka untuk menggantikan induk puyuh dalam menetaskan telurnya, dibuatlah mesin penetas telur puyuh. Namun mesin penetas telur yang beredar di pasaran saat ini masih terdapat kelemahan yang dapat menyebabkan hasil penetasan telur puyuh tidak maksimal. Alat penetas telur ini tidak dapat mengukur suhu dalam ruangan karena belum dilengkapi alat pengukur suhu sehingga peternak harus mengontrol setiap harinya dengan rentang waktu tertentu. Kemudian tingkat keberhasilan penetasan telur ini berkisar antara 50\% - 70\% dikarenakan temperatur suhu yang tidak bisa stabil.

Berangkat dari hal tersebut, timbul ide untuk meningkatkan proses produksi puyuh dengan menggunakan alat penetas telur puyuh berbasis mikrokontroler yang dapat mengkondisikan bibit unggul yang akan dihasilkan dengan pengaturan kualitas suhu dan intensitas cahaya yang akurat dan baik, akhirnya disusunlah permasalahan tersebut kedalam sebuah penelitian dengan tujuan terciptanya alat penetas telur puyuh berteknologi modern dan mudah cara pengoperasiannya.

\section{TINJAUAN PUSTAKA}

Penelitian dari Akhbar Prachaessardhi Rusdi tentang pengembangan bahan bakar alternatif bioetanol. Proses pembuatannya terdiri dari ekstraksi gula dari bahan nabati, fermentasi menggunakan bahan-bahan kimiawi, distilasi dan absorbsi. Dalam penelitian ini dilakukan distilasi mendekati kondisi vakum dan pada suhu tertentu sebagai pengganti dari proses absorbsi yang dapat memakan waktu 2-3 hari. Oleh karena itu, dibutuhkan kontroler yang dapat menjaga tekanan dan suhu pada kondisi tertentu. Pada penelitian ini hanya dirancang kontroler untuk pengendalian suhu. Metode yang digunakan adalah kontrol logika fuzzy. Keunggulannya adalah terdapat rule yang dapat di rancang sendiri sehingga suhu yang diinginkan pada proses distilasi dapat terjaga. Kesamaan dan keterkaitan penelitian diatas dengan penelitian penulis yaitu pengendalian suhu menjadi faktor utama dalam menjaga dan membaca keadaan terutama kesesuaian suhu dalam proses pembuatan bioetanol dan alat tetas telur. Adapun perbedaan penelitian diatas dengan penelitian penulis yaitu pada sensor suhu penelitian ini tidak dapat memberikan data suhu kepada device lain sedangkan sensor suhu tetas telur mampu mengirim data suhu dalam ruangan dan 
menjadi pengendali utama alat tetas telur. Dari sinilah muncul ide dan gagasan membuat alat tetas telur yang tidak hanya mampu bekerja otomatis namun dapat memberikan feedback kepada device pendukung lain seperti GSM Shield untuk mendapatkan informasi suhu dalam ruangan.[1]

Kemudian penelitian dari Nova El Maidah tentang Pengendalian Perangkat keras berbasis mikrokontroler sebagai pengendali suhu dan kelembapan. Rancangan ini dibuat agar mikrokontroler dapat berfungsi sebagai pengendali suhu dan kelembaban berdasarkan logika fuzzy. Menggunakan sistem RFID sebagai pemicu kerja sistem pengendali, DHT 11 sebagai sensor suhu dan kelembaban, thermoelectric cooler dan kipas sebagai aktuator sistem serta LCD16*2, LED, dan buzzer sebagai penampil pengguna. Metode yang digunakan pada penelitian ialah metode kontrol logika Fuzzy. Keunggulannya adalah sistem mampu merespon adanya perubahan error suhu dan kelembaban, sehingga parameter pengendali sistem akan berubah pula berdasarkan perubahan error yang terjadi. Kesamaan dan keterkaitan penelitian ini dengan penelitian penulis yaitu informasi data dari pembacaan sensor suhu dapat dijadikan sebagai pengambilan keputusan untuk memposisikan suhu pada setpoint.Sedangkan yang membedakan penelitian diatas dengan penelitian penulis ialah pengendalian suhu dilakukan secara manual untuk memperoleh setpoint tersebut, sedangkan penelitian alat tetas telur ini menggunakan satu perangkat DHT11 sebagai pengendalian suhu dan kelembapan yang bekerja secara otomatis yang dieksekusi oleh perangkat pendukung. Dari penjelasan diatas memperkuat ide dan konsep untuk merancang dan membuat alat tetas telur berbasis mikrokontroler dengan sensor DHT11 (suhu dan kelembapan), sebagai pengendali suhu otomatis dalam memonitoring objek.[2]

Penelitian sugihartono dengan tema "pengaruh perbedaan suhu teradap penetasan telur ikan gurami. Pada penelitian ini dilakukan perbedaan suhu yang dapat mempengaruhi terhadap keberhasilan penetasan telur ikan gurami. Suhu yang baik untuk penetasan telur ikan gurami adalah $30^{\circ} \mathrm{C}-32^{\circ} \mathrm{C}$ dapat menetaskan telur gurami sebesar 98,05\% dengan kualitas air mendukung kehidupan ikan [3].

Awaluddin telah melakukan penelitian dengan judul " Tingkat penetasan telur dan kelangsungan hidup larva kerang mutiara (pinctada maxima) pada salinitas yang berbeda. Hasil dari penelitian ini menunjukkan bahwa salinitas media berpengaruh nyata terhadap tingkat penetasan telur dan kelangsungan hidup larva $(p<0,05)$. Tingkat penetasan telur dan kelangsungan hidup tertinggi diperoleh pada salinitas 34 ppt dengan nilai $95.8 \%$ dan $72 \%$ dan terendah pada salinitas 25 ppt yaitu $72.5 \%$ dan $38 \%$. Selama penelitian kualitas air masih berada pada kisaran yang baik untuk kondisi telur dan larva kerang mutiara [4].

Putri telah melakukan penelitian dengan judul "Pesentase penetasan telur ikan betok (anabas testudineus) dengan suhu inkubasi yang berbeda. Dari hasil penelitian dinyatakan bahwa suhu $\left(31-34^{\circ} \mathrm{C}\right)$ berpengaruh terhadap waktu penetasan telur ikan betok tetapi tidak berpengaruh nyata terhadap persentase penetasan telur ikan betok [5]. Heltonika telah melakukan penelitian dengan judul"Pengaruh salinitas terhadap penetasan telur ikan jambal siam (pangasius hypohthalmus)". Hasil penelitian ini menyatakan bahwa salinitas berpengaruh terhadap penetasan dan daya tetas, salinitas 4 memberikan hasil terbaik, sedangkan dari kelangsungan hidup salinitas 6 memberikan hasil yang terbaik [6].

\section{METODE PENELITIAN}

Penelitian ini diawali dengan Observasi langsung untuk mengetahui data-data primer dalam penetasan telur berupa ( Suhu, Telur, dan konsep lama). Kemudian diteruskan dengan wawancara langsung dengan peternak puyuh untuk mengetahui kondisi dan keluhan yang dialami. Dan terakhir studi pustaka untuk memperkuat konsep usulan, mencari ide - ide sebagai perencanaan awal sehingga dirumuskan ke dalam sebuah perancangan.kemudian dikembangkan ke perencanaan sistem kerja beserta perangkat yang diperlukan untuk menunjang sistem yang telah dirancang. Setelah semua perancangan sistem selesai, kemudian perancangan instrument dan merangkai ke dalam blok blok rangkaian. Ketika sudah sesuai barulah masuk proses pembuatan program sesuai alur yang direncanakan di awal. Setelah program dan rangkaian selesai dibuat kemudian melakukan uji coba dan mengevaluasi setelah memperoleh hasil yang didapatkan [7]. 


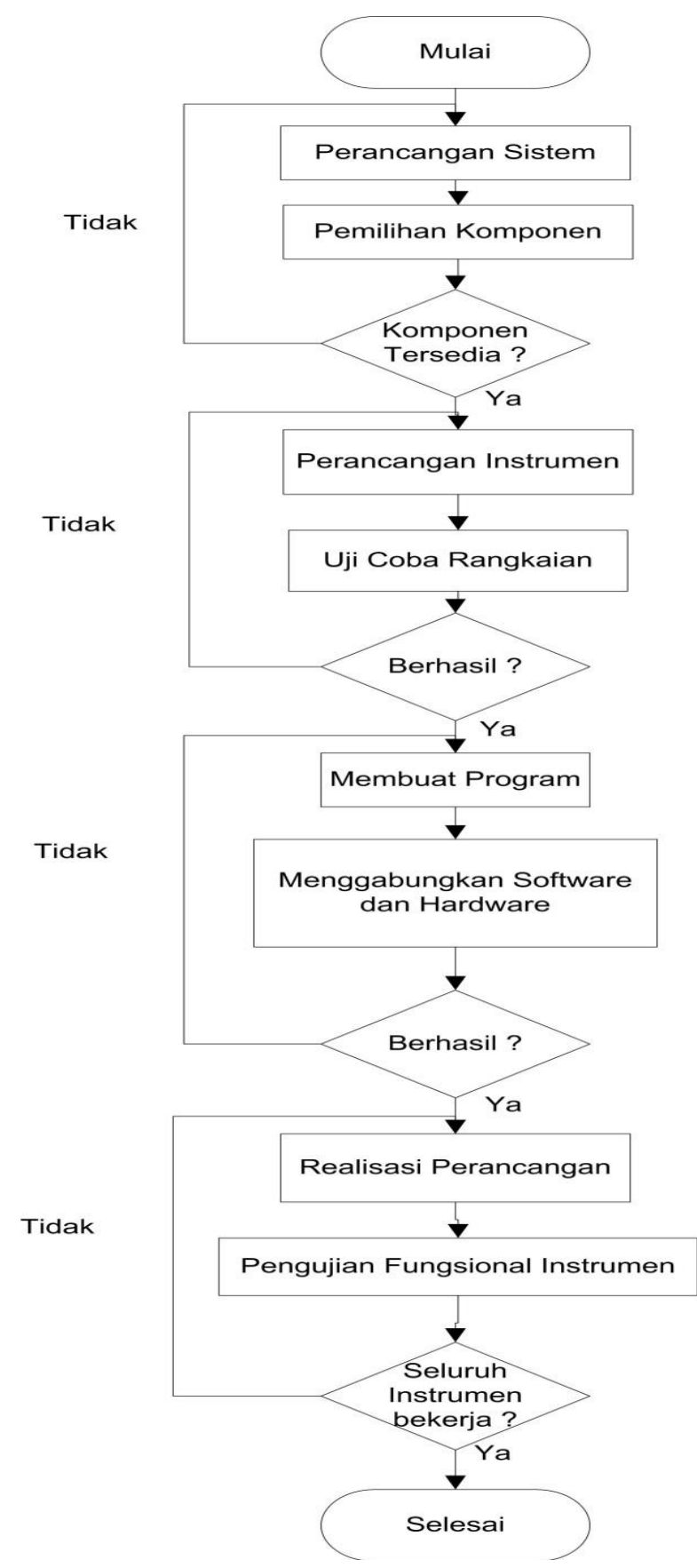

Gambar 1. Diagram Alur Prosedur Kerja

\subsection{Perancangan Hardware}

Ruang mesin penetas dibuat dari bahan multiplek berbentuk kotak persegi dengan ukuran $\mathrm{P} \times \mathrm{L} \times \mathrm{T}(50 \times 35 \times 50)$ seperti terlihat dibawah ini :

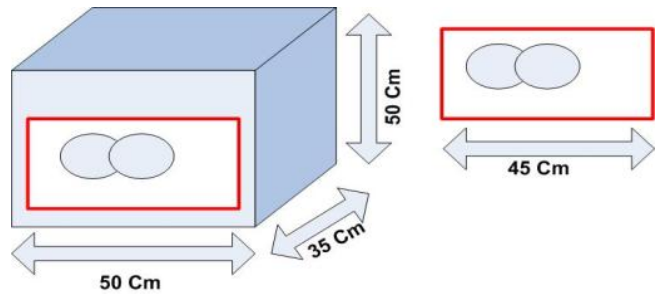

Gambar 2. Desain Box Incubator

Potong papan triplek dan kayu balok sesuai ukuran desain yang telah ditentukan, haluskan sisa potongan dengan menggunakan amplas, dilanjutkan dengan menyatukan potongan - potongan tadi dengan lem kayu untuk merekatkan antar bagian, kemudian dipaku agar menjadi lebih kuat [8].

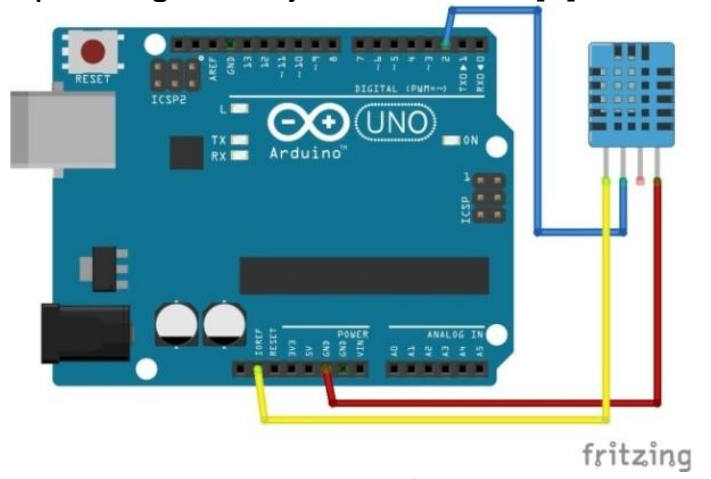

Gambar 3. Rangkaian sensor DHT11

Dimana sensor ini dipakai untuk mendeteksi suhu dalam inkubator telur puyuh, DHT 11 memiliki 3 buah pin yang terdiri dari pin VCC, DATA, dan GND. Pin VCC dihubungkan dengan tegangan $5 \mathrm{~V}$, pin GND ke ground, dan pin DATA ke pin 2.

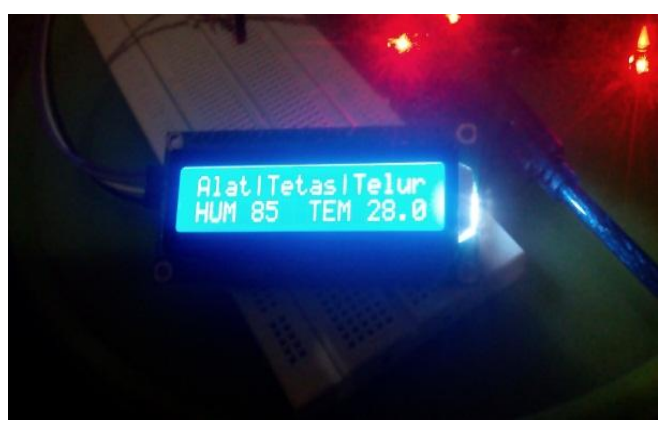

Gambar 4. Tampilan LCD

Pin LCD dihubungkan ke pin port I2C, kemudian pin VCC dihubungkan dengan tegangan $5 \mathrm{~V}$, pin GND ke ground,pin SDA sesuaikan dengan pin SDA dan pin SCL disesuaikan dengan pin SCL.

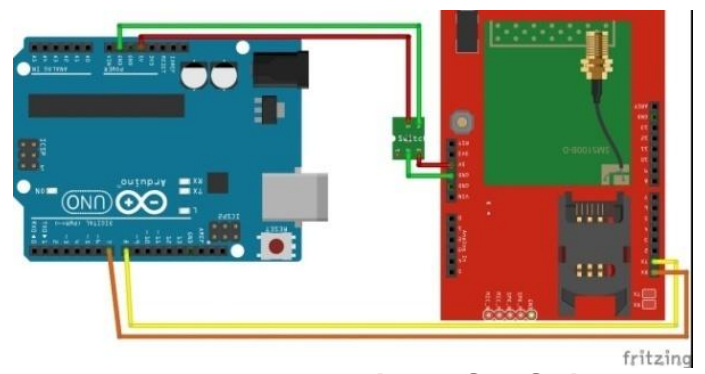

Gambar 5. Rangkaian GSM Shield

Pin VCC dihubungkan dengan tegangan $5 \mathrm{~V}$, pin GND dihubungkan dengan pin ground, Pin RX pada sim800 dihubungkan dengan pin 6 pada Arduino dan Pin TX pada sim800 dihubungkan dengan pin 7 pada arduino sesuai library yg digunakan [9]. 


\subsection{Perangkat Lunak}

Perangkat lunak sangatlah dibutuhkan. Salah satu perangkat lunak yang digunakan adalah arduino compiler versi 1.05. Perangkat lunak digunakan sebagai pembuatan program serta compiling script program menjadi bahasa mesin agar perintah yang diketikkan pada program dapat dibaca dan dilaksanakan oleh chip ATMega 328 yang terdapat pada board Arduino Uno. Arduino compiler juga dapat melakukan proses uploading program yang ditanamkan pada chip ATMega 328 di board arduino Uno tersebut. Keunggulan lainnya adalah menggunakan bahasa pemrograman high level language sehingga dalam penggunaannya tergolong sangat mudah digunakan. Softwer arduino compiler sangat kompatibel dengan system opoerasi Windows $X P$, Windows Seven dan Windows 8. Perancangan program yang digunakan untuk pembuatan sistem pada penetas telur otomatis dimulai dengan membuat flowchart program. Flowchart digunakan sebagai pedoman dalam pembuatan program secara keseluruhan. Flowchart program keseluruhan penetas telur dapat dilihat pada Gambar 6 [10].

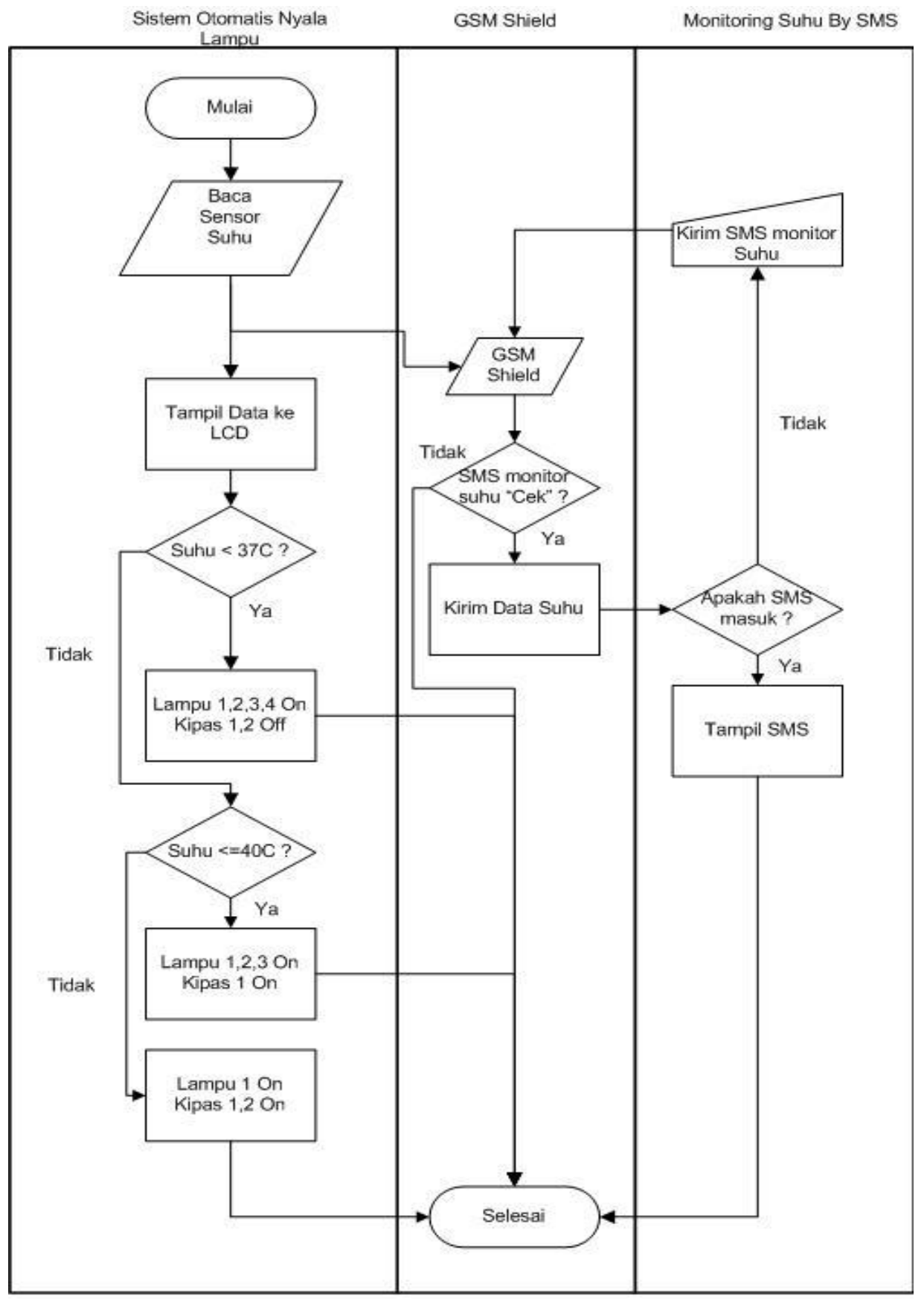

Gambar 6. Flowchart Sistem 


\section{HASIL DAN PEMBAHASAN}

Penetas telur ini dibuat dengan menggunakan inputan dari sensor DHT11 dengan output digital yang diproses pada board arduino dan masukan berupa sms yang nantinya sebagai perintah yang akan dieksekusikan. Keluaran dari alat penetas ini berupa tampilan visual LCD, kipas DC sebagai penambah kelembapan dan lampu sebagai penghasil suhu.

Tabel 1. Hasil Pengujian Alat Penetas Telur manual

\begin{tabular}{|c|c|c|c|}
\hline \multicolumn{4}{|c|}{ Penetas Manual } \\
\hline \multicolumn{3}{|c|}{ Telur Menetas } & $\begin{array}{c}\text { Tidak } \\
\text { Menetas }\end{array}$ \\
\hline \multicolumn{3}{|c|}{$12(80 \%)$} & \multirow{4}{*}{$\begin{array}{c}3 \text { Telur } \\
20 \%\end{array}$} \\
\hline Normal & Cacat & Mati & \\
\hline 10 & 0 & 2 & \\
\hline $66 \%$ & 0 & $13 \%$ & \\
\hline
\end{tabular}

Tabel 2. Hasil Pengujian Alat Penetas Telur Otomatis

\begin{tabular}{|c|c|c|c|}
\hline \multicolumn{4}{|c|}{ Penetas Otomatis } \\
\hline \multicolumn{3}{|c|}{ Telur Menetas } & $\begin{array}{c}\text { Tidak } \\
\text { Menetas }\end{array}$ \\
\hline \multicolumn{3}{|c|}{$14(93 \%)$} & \multirow{4}{*}{$\begin{array}{c}1 \text { Telur } \\
6,6 \%\end{array}$} \\
\hline Normal & Cacat & Mat & \\
\hline 11 & 3 & 0 & \\
\hline $60 \%$ & $20 \%$ & 0 & \\
\hline
\end{tabular}

Ketentuan Uji Coba

- Suhu 38 C

- Percobaan 15 butir Telur

- Ukuran Bok 50x 35x $50 \mathrm{~cm}$

- 60 Watt Lampu Pijar

Dari percobaan menggunakan penetas telur manual didapatkan persentase penetasan $80 \%$, dengan $66 \%$ dalam keadaan normal dan $0 \%$ dalam keadaan cacat. Dari percobaan ini didapatkan $20 \%$ tidak menetas. Percobaan menggunakan penetas telur yang penulis buat didapatkan persentase penetasan 93\%, dengan $60 \%$ dalam keadaan normal dan $20 \%$ dalam keadaan cacat serta telur yang tidak menetas $6,6 \%$. Cacat disini adalah hasil tetasan tidak dapat berdiri dan berjalan secara normal.

Berdasarkan tabel diatas maka hasil perbandingan dengan penetas telur manual di dapatkan kesimpulan sebagai berikut :

Kelebihan :

1. Pembacaan Sensor DHT11 berjalan sesuai alur sistem yang telah dibuat dan akurat dalam pembacaan suhu ruangan.

2. Display LCD dapat menampilkan hasil pembacaan dari sensor DHT11 yang diolah arduino.

3. Sebaran Suhu dan Kelembapan telah bekerja dengan baik, dimana suhu di dalam boks dapat dipertahankan pada kondisi $37^{\circ} \mathrm{C}-40^{\circ} \mathrm{C}$ dan kelembaban dapat dipertahankan pada kondisi $55 \%$ $\mathrm{RH}-75 \% \mathrm{RH}$.

Kekurangan :

1. Daya tampung telur yang sedikit.

2. Monitoring dengan SMS bekerja cukup baik dalam mengeksekusi perintah, namun terkendala dengan sinyal yang tidak bisa stabil.

\section{PENUTUP}

\subsection{Kesimpulan}

Dari hasil perancangan, pembuatan, pengaplikasian alat tetas telur ini dapat disimpulkan sebagai berikut:

1. Terciptanya penetas telur otomatis menggunakan sistem berbasis Arduino Uno dan dengan bahasa pemrograman Arduino.

2. Alat penetas telur telah bekerja sesuai data sheet suhu dan kelembapan yang telah diatur, yaitu mempertahankan suhu pada kondisi $37^{\circ} \mathrm{C}-40^{\circ} \mathrm{C}$ dan kelembaban pada kondisi $55 \% \mathrm{RH}-75 \% \mathrm{RH}$.

\subsection{Saran}

Berdasarkan proses yang telah dialami, penulis memberikan saran kepada pihak-pihak yang hendak mengembangkan tentang Penetas Telur Otomatis ini antara lain:

1. Mendesain boks penetas menggunakan bahan yang tahan terhadap panas dan dapat mempertahankan suhu dan kelembaban yang standar di dalam boks.

2. Menggunakan pemanas dengan respon yang cepat.

3. Mempersiapkan cadangan listrik apabila sewaktu - waktu terjadi pemadaman listrik.

4. Bisa melakukan percobaan menggunakan jenis telur selain telur puyuh dengan mengetahui standar suhu pada tiap-tiap jenisnya.

\section{DAFTAR PUSTAKA}

[1] Akhbar Prachaessardhi Rusdi, "Sistem Pengendalian Suhu Pada Proses 
Distilasi Vakum Bioetanol," Februari 2014.

[2] Nova El Maidah, "Perancangan Perangkat Keras Pengendali Fuzzy," November 2012.

[3] Muhammad sugihartono dan Masdinar dalimunthe, Pengaruh Perbedaan Suhu Terhadap Penetasan Telur Ikan Gurami ( Osphronemus Gouramy Lac),Jurnal IImiah Universitas Batanghari Jambi Vol.10 No.3 Tahun 2010.

[4] Muhammad Awaluddin dan Salnida Yuniarti ,Tingkat penetasan telur dan kelangsungan hidup larva kerang mutiara (pinctada maxima) pada salinitas yang berbeda, Jurnal Kelautan Vol 6, No.2, Oktober 2013, ISSN:1907-9931.

[5] Dwi aprilianti putri dan Muslim, Persentase Penetasan Telur Ikan Betok (Anabas Testudineus) Dengan Suhu Inkubasi Yang Berbeda, Jurnal Akuakultur Rawa Indonesia tahun 2013, 1(2):184-191 (2013), ISSN:2303-2960.

[6] Benny Heltonika, Pengaruh Salinitas Terhadap Penetasan Telur Ikan Jambal Siam (Pangasius Hypohthalmus), Jurnal Akuakultur Rawa Indonesia, 2(1): 1323(Tahun 2014), ISSN:2303-2960.

[7] Annie Sailendra, Standard Operating Procedures, Eista Swaesti, Ed. Jogjakarta: Trans Idea Publishing, 2015.

[8] Arief Budi Laksono, Affan Bachri, dan Sukin, "Rancang Bangun Otomatisasi Mesin Penetas Telur Sistem Turning Berbasis Mikrokontroler Atmega 328," Jurnal Teknik Elektro, Vol. 1, No. 2, 2016, ISSN: 2502-0986.

[9] Heri Andrianto, Arduino Pemrograman. Bandung: Informatika Bandung, 2016.

[10] Aan Darmawan, Belajar Pemrograman Arduino. Bandung: Informatika Bandung, 2016. 